\title{
Clinical Guidelines
}

Clinical nephron

Practice

\section{KDIGO Clinical Practice Guidelines for Acute Kidney Injury}

\author{
Arif Khwaja \\ Sheffield Kidney Institute, Northern General Hospital, Sheffield, UK
}

\section{Introduction}

Acute kidney injury (AKI) is an increasingly common clinical problem faced by nephrologists and intensivists, as well as general physicians and surgeons. AKI is associated with adverse outcomes both in the short and long term with chronic kidney disease (CKD) being increasingly recognised as a common sequela of AKI. In an analysis of 19,982 consecutive admissions in a single centre in Boston, USA, AKI was significantly associated with mortality, length of stay and healthcare cost [1]. Elevations in serum creatinine were common, affecting up to $13 \%$ of patients, and even relatively modest elevations in serum creatinine were associated adverse outcomes - a rise in serum creatinine of $\geq 0.5 \mathrm{mg} / \mathrm{dl}(44 \mu \mathrm{mol} / \mathrm{l})$ was associated with 6.5 -fold increase in the risk of death. The inadequacies of AKI management were highlighted by a recent UK government survey where the care of AKI was deemed inadequate in $33 \%$ of cases, with poor recognition of risk factors such as sepsis and hypovolaemia [2]. The pattern and burden of AKI appears to be particularly significant in developing countries [3] and therefore the recently published Kidney Disease Improving Global Guidelines (KDIGO) Clinical Practice Guidelines for Acute Kidney Injury provides a welcome and timely synthesis of the evidence base to support the management of AKI [4].

As in previous guidelines, KDIGO utilised a grading system with level 1 being rated a 'strong recommenda- tion', implying that most patients 'should' receive a particular action. In contrast, level 2 guidelines are essentially 'suggestions' and are deemed to be 'weak' or discretionary, recognising that management decisions may vary in different clinical contexts. Each recommendation was further graded from $A$ to $D$ by the quality of evidence underpinning them, with grade A referring to a high quality of evidence whilst grade D recognised a 'very low' evidence base. The overall strength and quality of the supporting evidence is summarised in table 1 .

The guidelines focused on 4 key domains: (1) AKI definition, (2) prevention and treatment of AKI, (3) contrastinduced AKI (CI-AKI) and (4) dialysis interventions for the treatment of AKI. The full summary of clinical practice statements is available at www.kdigo.org, but a few key recommendation statements will be highlighted here.

\section{AKI Definition}

A key recommendation is that clinicians effectively adopt the previously published AKI Network definition of AKI [5] as one of the following:

- An increase in serum creatinine by $\geq 0.3 \mathrm{mg} / \mathrm{dl}(\geq 26.5$ $\mu \mathrm{mol} / \mathrm{l})$ within $48 \mathrm{~h}$

- An increase in serum creatinine to $\geq 1.5$ times baseline within the previous 7 days

- Urine volume $\leq 0.5 \mathrm{ml} / \mathrm{kg} / \mathrm{h}$ for $6 \mathrm{~h}$

\section{KARGER}

Fax +4161306 1234

E-Mail karger@karger.ch

www.karger.com
(C) 2012 S. Karger AG, Basel

$1660-2110 / 12 / 1204-0179 \$ 38.00 / 0$

Accessible online at: www.karger.com/nec
Dr. Arif Khwaja, PhD, FRCP

Sheffield Kidney Institute, Northern General Hospital Herries Road

Sheffield S5 7AU (UK)

Tel. +44 114271 4808, E-Mail arif.khwaja@ @th.nhs.uk 
Table 1. Summary of evidence level and strength of KDIGO recommendations

\begin{tabular}{lcrl}
\hline Quality of supporting evidence & Level 1 & Level 2 & Not graded \\
\hline A & $9(14.8 \%)$ & $2(3.3 \%)$ & 26 statements not \\
B & $10(16.4 \%)$ & $10(16.4 \%)$ & graded \\
C & $3(4.9 \%)$ & $20(32.8 \%)$ & \\
D & $0(0 \%)$ & $7(11.5 \%)$ & \\
\hline
\end{tabular}

Table 2. Proposed KDIGO staging of AKI

\begin{tabular}{|c|c|c|}
\hline Stage & Serum creatinine & Urine output \\
\hline 1 & $\begin{array}{l}1.5-1.9 \text { times baseline } \\
\text { or } \\
\geq 0.3 \mathrm{mg} / \mathrm{dl}(\geq 26.5 \mu \mathrm{mol} / \mathrm{l}) \text { increase }\end{array}$ & $<0.5 \mathrm{ml} / \mathrm{kg} / \mathrm{h}$ for $6-12 \mathrm{~h}$ \\
\hline 2 & 2.0-2.9 times baseline & $<0.5 \mathrm{ml} / \mathrm{kg} / \mathrm{h}$ for $\geq 12 \mathrm{~h}$ \\
\hline 3 & $\begin{array}{l}3 \text { times baseline } \\
\text { or } \\
\geq 4.0 \mathrm{mg} / \mathrm{dl}(\geq 353.6 \mu \mathrm{mol} / \mathrm{l}) \text { increase } \\
\text { or } \\
\text { initiation of } \mathrm{RRT} \\
\text { or } \\
\text { in patients }<18 \text { years a decrease in eGFR } \\
<35 \mathrm{ml} / \mathrm{min} / 1.73 \mathrm{~m}^{2}\end{array}$ & $\begin{array}{l}<0.3 \mathrm{ml} / \mathrm{kg} / \mathrm{h} \text { for } \geq 24 \mathrm{~h} \\
\text { or } \\
\text { anuria } \geq 12 \mathrm{~h}\end{array}$ \\
\hline
\end{tabular}

Furthermore, KDIGO suggests that AKI should be staged according to severity as outlined in table 2 . The rationale for the staging system comes from a plethora of studies showing that the risk of death and renal replacement therapy (RRT) increases with each stage [6-8]. Furthermore, evidence suggesting patients in whom AKI resolves are at increased risk of death, CKD and cardiovascular disease $[9,10]$ has prompted KDIGO to make an ungraded suggestion that all those with resolved AKI should be considered to be at increased risk of CKD and be managed as per the KDOQI guidelines for individuals at risk of CKD. Other recommendations include stratifying patients for risk of AKI and monitoring serum creatinine at urine output in those at risk as well as those with established AKI.

The limitations of any classification system based on serum creatinine in patients who are likely to be catabolic and not in steady state are recognised by the guidelines. Furthermore, the effects of age and pre-existing sarcopenia on the accuracy of the classification system are not clearly discussed, but they are likely to impact on the accuracy of any creatinine-based classification system. Clearly knowing the baseline serum creatinine is essential in utilising the classification system as AKI often begins before patients are admitted to hospital, and for many pa- tients there is no record of baseline kidney function. Controversially, the guidelines suggest that patients should be assumed to have a baseline eGFR of $75 \mathrm{ml} / \mathrm{min} / 1.73 \mathrm{~m}^{2}$ in cases where there is no history of CKD and baseline kidney function is unknown. Although this approach has been validated in AKI epidemiology studies in clinical settings, many clinicians may be reluctant to make such assumptions and there is an inherent risk that many patients would be inappropriately labeled as having AKI without any outcome data to show that such labeling will improve patient outcomes. Similarly, the use of urine output as a diagnostic criterion is less well established. However, until the use of biomarkers such as N-Gal and Kim1 can be conclusively shown to improve patient outcomes in AKI (rather than facilitate earlier diagnosis), the clinical reality is that serum creatinine combined with urine output will remain the cornerstone for diagnosing AKI.

There is no doubt that standardising the definition and staging of AKI provides a clear framework for studying outcomes in both epidemiological and clinical research. However, the definition and staging of AKI is ungraded - reflecting the fact that it cannot be subjected to systemic review. The KDIGO work group argued that ungraded statements 'should not be viewed as weaker than graded recommendations'. However, the bedside utility 
of the proposed classification and staging may be questioned by many 'real world' practicing clinicians who would view such statements as being opinion-based rather than evidence-based. In particular, it is not clear how staging will alter immediate management and outcomes.

Furthermore, whilst a recommendation is made to treat those with resolved AKI as being at increased risk of $\mathrm{CKD}$, no specific guidance is given on the nature or frequency of such monitoring, nor is there any data to show the cost-effectiveness of such a strategy.

\section{Prevention and Treatment of AKI}

A total of 25 practice statements are made in this section, many of which seem eminently sensible, such as the 'use of vasopressors in conjunction with fluids in patients with vasomotor shock' (level 1C). Importantly, the guidelines critically review the evidence for a number of agents which have been evaluated in the prevention and treatment of AKI, all of which have failed to show any consistent benefit including dopamine (level 1A), fenoldopam (a pure dopamine type-1 receptor agonist without $\alpha$ - and $\beta$-adrenergic stimulation; level $2 \mathrm{C}$ ), atrial natriuretic peptide (level 2C), insulin-like growth factor-1 (level 1B) and diuretics (level 1B). There is no role for any of these agents in the management of AKI though the guidelines acknowledge that diuretics may be useful in the management of volume overload.

A number of other recommendations are made including:

- The use of isotonic crystalloids rather than colloids for volume expansion (level 2B), based on randomised controlled trials such as Saline versus Albumin Fluid Evaluation comparing albumin with isotonic saline in an intensive care setting, which found no difference in outcomes [11]. Furthermore, a recent meta-analysis showed certain preparations of colloids such as hyperoncotic starch are actually associated with AKI [12].

- Insulin therapy to target plasma glucose of 110-149 $\mathrm{mg} / \mathrm{dl}$ (6.1-8.3 mmol/l; level 2C). This may be a somewhat controversial recommendation as these thresholds have not been examined in a randomised controlled trial and the risks of hypoglycaemia are significant with a meta-analysis of intensive insulin therapy trials showing an increased risk of death in those with hypoglycaemia [13].

- Avoiding aminoglycosides (level 2A) if possible and using single-daily dosing (level $2 \mathrm{~B}$ ) with therapeutic drug monitoring (level 1A).

KDIGO Clinical Practice Guidelines for AKI
- Using liposomal amphotericin or azoles and/or echinocandins for fungal and parasitic infections (level 2A).

- Avoiding the use of oral or intravenous $\mathrm{N}$-acetylcysteine (NAC) for the prevention of postsurgical AKI (level 1A).

\section{Contrast-Induced Acute Kidney Injury}

The incidence of CI-AKI has been reported to be around $10.5 \%$ [14], with mortality as high as 35\% in those who require dialysis [15]. Clearly it is difficult to tease out the role of confounding variables, but the CI-AKI remains a pressing clinical problem.

A number of recommendations are made by KDIGO including:

- Assess risk for CI-AKI and screen for kidney disease in those who require iodinated contrast, which may be achieved by point-of-care creatinine testing or by questionnaire-based risk assessment for factors such as diabetes, cardiovascular disease and CKD (not graded).

- Avoid/minimise contrast if possible in those at risk of CI-AKI (not graded) and use iso-osmolar or low-osmolar contrast in those with increased risk (level 1B). In the head-to-head comparisons of iso-osmolar versus low-osmolar contrast, no definitive differences in incidence of CI-AKI were found.

- Use of intravenous saline or sodium bicarbonate in those at risk of CI-AKI (level 1A). A comprehensive review of 23 studies comparing bicarbonate to saline found no clear evidence that bicarbonate was superior to saline [16].

- Use of oral NAC with fluids in those at risk (level 2D).

- No role for oral fluids alone (level 1C).

- No role for haemodialysis/haemofiltration for contrast removal in those with increased risk of CI-AKI (level 2C).

It is worth pointing out that despite the recommendation for intravenous fluid loading rather than oral fluid loading, there is little head-to-head comparison between the two approaches. The volume of fluid ingested appears to be an important predictor of CI-AKI and a recent study of oral versus intravenous fluids found no difference in CI-AKI in mild CKD $[17,18]$. Given the expense of intravenous therapy for all at risk of CI-AKI, the use of oral fluid loading may be justified in those 'well' outpatients with mild CKD. 
Table 3. Key recommendations for dialysis interventions for treatment of AKI

Recommendation

Anticoagulation

Use anticoagulation in RRT as long as no impaired coagulation/bleeding risk

Unfractionated or low-molecular-weight heparin for intermittent RRT

Regional citrate preferred for CRRT

Unfractionated or low-molecular-weight heparin in CRRT in those with contraindication to citrate; no role for

prostacyclins

Regional citrate in CRRT for those with at increased bleeding risk - avoid regional heparinisation

Stop all heparin and use direct thrombin inhibitors (argatroban) or factor Xa inhibitors (danaparoid or

fondaparinux) in heparin-induced thrombocytopenia - argatroban preferred if severe liver failure

\section{Access}

Choice of vein as follows:

(1) Right Jugular

(2) Femoral

(3) Left jugular

(4) Subclavian - dominant side

Ultrasound-guided insertion $1 \mathrm{~A}$

No use for topical antibiotics or antibiotic locks

$2 \mathrm{C}$

Modality

CRRT preferred to intermittent haemodialysis for those with:

(1) Cardiovascular instability

(2) Acute brain injury or cerebral oedema or raised intracranial pressure

Buffer

Use of bicarbonate rather than lactate as a buffer in those with associated circulatory shock/liver failure/lactic acidosis

$1 \mathrm{~B}-2 \mathrm{~B}$

Dose

$\mathrm{Kt} / \mathrm{V}$ of 3.9 per week for those on intermittent or extended RRT

Effluent volume of $20-25 \mathrm{ml} / \mathrm{kg} / \mathrm{h}$ for CRRT

$1 \mathrm{~A}$

$1 \mathrm{~A}$

Concerning NAC, the guidelines recognise that there is significant heterogeneity in the data and the effects appear modest, but support its use on the grounds that it is a cheap and safe intervention. It is worth noting that the oral bioavailability of NAC may be less than $10 \%$ and interpretation of its effects in CI-AKI may be confounded by the action of NAC on tubular secretion of creatinine.

Finally, there is conflicting data regarding the value of prophylactic haemodialysis/haemofiltration on CI-AKI, which is reflected in the level $2 \mathrm{C}$ grading of the guideline [19-21].

\section{Dialysis Interventions for the Treatment of AKI}

This section of the guidelines covers a variety of issues including initiation and withdrawal of RRT, anticoagulation, vascular access, membrane use, modality and dose of RRT, and buffer solution use. A total of 30 recommendation statements are made and some of the key recommendations are summarised in table 3.

The use of citrate is recommended for patients on continuous RRT (CRRT), mainly on the basis of a large randomised controlled trial involving 200 patients showing that its use was associated with fewer complications (e.g. bleeding and thrombocytopenia) [22]. It is important to note that the comparator arm was given low-molecularweight heparin without any monitoring which may have driven the event rate in that group. The requirements for complex protocols with additional calcium infusions and intensive monitoring may limit the widespread use of citrate in CRRT. Furthermore, citrate is contraindicated in those with liver disease or shock states - the very patients who are most likely to require CRRT on the intensive care.

The suggestion that CRRT be used rather than intermittent haemodialysis for haemodynamically unstable 
patients again contrasts with the actual evidence as set out in a Cochrane meta-analysis, which failed to show any difference in haemodynamic instability or mortality between the two modalities [23]. Whilst CRRT appeared to be associated with less escalation of vasopressors with higher mean arterial pressure at the end of therapy, it also appeared to be associated with a higher risk of clotted filters. Furthermore, there is little data comparing CRRT to either sustained low-efficiency dialysis (SLED) or protocol-driven management to improve the stability of haemodialysis (e.g. dialysate cooling, sodium profiling, stopping vasodilator therapy, 'extended slow' dialysis). There is scant data on the feasibility of peritoneal dialysis in the management of AKI and its use appears to be primarily limited to the paediatric population or resource-poor areas.

The guidelines recommend dialysis dose be measured though the use of $\mathrm{Kt} / \mathrm{V}$ as a marker of dialysis dose in AKI, but this is fraught with difficulty given the variations in urea generation with patients not being in steady state. The recommended Kt/V of 3.9 appears to be derived from the Veterans Affairs/NIH Acute Renal Failure Trial Network. While this large randomised controlled trial failed to show any benefit of increasing RRT dose, the average $\mathrm{Kt} / \mathrm{V}$ in the less intensive group was 3.9 per week [24]. Those patients on CRRT in this trial had a minimum effluent flow of $20 \mathrm{ml} / \mathrm{kg} / \mathrm{h}$ whilst a large study of CRRT dose from Australasia showed no difference between effluent flow rates of 25 and $40 \mathrm{ml} / \mathrm{kg} / \mathrm{h}$ - hence the recommendation of a minimum effluent volume of $20-25 \mathrm{ml} / \mathrm{kg} / \mathrm{h} \mathrm{[25].}$

\section{Conclusions}

As with previous KDIGO guidelines, the recommendations on AKI are based on an exhaustive evidencebased review of the literature and provide welcome guidance for practice for clinicians. The clear message is that there is a lack of evidence (particularly, well-designed interventional outcome studies) to underpin much of our everyday clinical practice. Indeed only $14.8 \%$ of the recommendations were graded ' $1 \mathrm{~A}$ ' whilst $63.9 \%$ of the recommendations were level 2 . Thus, these are not prescriptive guidelines, but provide nuanced guidance for the clinician. The KDIGO co-chairs bullishly argue that recommendations should be made even when the evidence is weak, as clinicians often ask 'What do the experts do?' - this may be true, but as history tells us, the track record of expert opinion in the absence of evidence can often be deeply flawed. Thus, it is essential that practicing clinicians using these guidelines distinguish expert opinion from evidence-based recommendations and (as the KDIGO co-chairs recommend) use these guidelines to 'start, not stop, their inquiries into specific management questions'.

The recommendation that an empirical definition and staging system be used in the management of AKI will arouse controversy and debate. As of yet, no data has been presented to show that these tools in themselves can improve outcomes in AKI and many clinicians will be wary about implementing what is essentially a research-based diagnostic and staging system into the clinical arena in the absence of such data.

\section{References}

1 Chertow GM, Burdick E, Honour M, Bonventre JV, Bates DW: Acute kidney injury, mortality, length of stay, and costs in hospitalized patients. J Am Soc Nephrol 2005;16: 3365-3370.

2 NCEPOD Report. Acute Kidney Injury Adding Insult to Injury. 2009. http://www. ncepod.org.uk/2009aki.htm.

3 Cerda J, Bagga A, Kher V, Chakravarthi RM: The contrasting characteristics of acute kidney injury in developed and developing countries. Nat Clin Pract Nephrol 2008;4:138-153.

4 Clinical Practice Guidelines for Acute Kidney Injury 2012. http://www.kdigo.org/clinical_practice_guidelines/AKI.php.

$\checkmark 5$ Mehta RL, Kellum JA, Shah SV, Molitoris BA, Ronco C, Warnock DG, Levin A: Acute kidney injury network: report of an initiative to improve outcomes in acute kidney injury. Crit Care 2007;11:R31.

KDIGO Clinical Practice Guidelines for AKI
6 Ali T, Khan I, Simpson W, Prescott G, Townend J, Smith W, Macleod A: Incidence and outcomes in acute kidney injury: a comprehensive population-based study. J Am Soc Nephrol 2007; 18:1292-1298.

-7 Joannidis M, Metnitz B, Bauer P, Schusterschitz N, Moreno R, Druml W, Metnitz PG: Acute kidney injury in critically ill patients classified by AKIN versus RIFLE using the SAPS 3 database. Intensive Care Med 2009; 35:1692-1702.

-8 Thakar CV, Christianson A, Freyberg R, Almenoff P, Render ML: Incidence and outcomes of acute kidney injury in intensive care units: a Veterans Administration study. Crit Care Med 2009;37:2552-2558.
9 Coca SG, Yusuf B, Shlipak MG, Garg AX, Parikh CR: Long-term risk of mortality and other adverse outcomes after acute kidney injury: a systematic review and meta-analysis. Am J Kidney Dis 2009;53:961-973.

10 Wald R, Quinn RR, Luo J, Li P, Scales DC, Mamdani MM, Ray JG: Chronic dialysis and death among survivors of acute kidney injury requiring dialysis. JAMA 2009;302: 1179-1185.

11 Finfer S, Bellomo R, Boyce N, French J, Myburgh J, Norton R: A comparison of albumin and saline for fluid resuscitation in the intensive care unit. N Engl J Med 2004;350: 2247-2256.

- 12 Wiedermann CJ, Dunzendorfer S, Gaioni LU, Zaraca F, Joannidis M: Hyperoncotic colloids and acute kidney injury: a metaanalysis of randomized trials. Crit Care 2010;14:R191. 
13 Griesdale DE, de Souza RJ, van Dam RM, Heyland DK, Cook DJ, Malhotra A, Dhaliwal R, Henderson WR, Chittock DR, Finfer $\mathrm{S}$, Talmor D: Intensive insulin therapy and mortality among critically ill patients: a meta-analysis including NICE-SUGAR study data. CMAJ 2009;180:821-827.

14 Jabara R, Gadesam RR, Pendyala LK, Knopf WD, Chronos N, Chen JP, Viel K, King SB 3rd, Manoukian SV: Impact of the definition utilized on the rate of contrast-induced nephropathy in percutaneous coronary intervention. Am J Cardiol 2009;103:1657-1662.

15 McCullough PA, Wolyn R, Rocher LL, Levin $\mathrm{RN}$, O'Neill WW: Acute renal failure after coronary intervention: incidence, risk factors, and relationship to mortality. Am J Med 1997; 103:368-375.

16 Zoungas S, Ninomiya T, Huxley R, Cass A, Jardine M, Gallagher M, Patel A, VasheghaniFarahani A, Sadigh G, Perkovic V: Systematic review: sodium bicarbonate treatment regimens for the prevention of contrast-induced nephropathy. Ann Intern Med 2009; 151:631-638.
7 Yoshikawa D, Isobe S, Sato K, Ohashi T, Fujiwara Y, Ohyama H, Ishii H, Murohara T: Importance of oral fluid intake after coronary computed tomography angiography: an observational study. Eur J Radiol 2011;77: 118-122.

18 Cho R, Javed N, Traub D, Kodali S, Atem F, Srinivasan V: Oral hydration and alkalinization is noninferior to intravenous therapy for prevention of contrast-induced nephropathy in patients with chronic kidney disease. J Interv Cardiol 2010;23:460-466.

19 Cruz DN, Goh CY, Marenzi G, Corradi V, Ronco C, Perazella MA: Renal replacement therapies for prevention of radiocontrast-induced nephropathy: a systematic review. Am J Med 2012;125:66-78 e63.

-20 Lee PT, Chou KJ, Liu CP, Mar GY, Chen CL, Hsu CY, Fang HC, Chung HM: Renal protection for coronary angiography in advanced renal failure patients by prophylactic hemodialysis. A randomized controlled trial. J Am Coll Cardiol 2007;50:1015-1020.

21 Marenzi G, Lauri G, Campodonico J, Marana I, Assanelli E, De Metrio M, Grazi M, Veglia F, Fabbiocchi F, Montorsi P, Bartorelli AL: Comparison of two hemofiltration protocols for prevention of contrast-induced nephropathy in high-risk patients. Am J Med 2006;119:155-162.
22 Oudemans-van Straaten HM, Bosman RJ, Koopmans M, van der Voort PH, Wester JP, van der Spoel JI, Dijksman LM, Zandstra DF: Citrate anticoagulation for continuous venovenous hemofiltration. Crit Care Med 2009; 37:545-552.

23 Rabindranath K, Adams J, Macleod AM, Muirhead N: Intermittent versus continuous renal replacement therapy for acute renal failure in adults. Cochrane Database Syst Rev 2007;3:CD003773.

24 Palevsky PM, Zhang JH, O'Connor TZ, Chertow GM, Crowley ST, Choudhury D, Finkel K, Kellum JA, Paganini E, Schein RM, Smith MW, Swanson KM, Thompson BT, Vijayan A, Watnick S, Star RA, Peduzzi P: Intensity of renal support in critically ill patients with acute kidney injury. $\mathrm{N}$ Engl J Med 2008;359:7-20.

25 lomo R, Cass A, Cole L, Finfer S, Gallagher M, Lo S, McArthur C, McGuinness S, Myburgh J, Norton R, Scheinkestel C, Su S: Intensity of continuous renal-replacement therapy in critically ill patients. $\mathrm{N}$ Engl J Med 2009;361:1627-1638. 